\title{
Revista de la
}

\section{CEPAL}

Secretario Ejecutivo

Gert Rosenthal

Secretario Ejecutivo Adjunto

Carlos Massad

\section{Director de la Revista}

Aníbal Pinto

Secretario Técnico

Eugenio Lahera

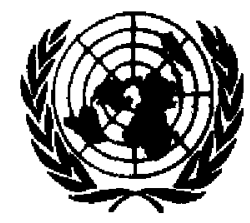

NACIONES UNIDAS

COMISION ECONOMICA PARA AMERICA LATINA Y EL CARIBE SANTIAGO DE CHILE, AGOSTO DE 1992 


\section{Revista de la}

\section{CEPAL}

Santiago de Chile

Agosto de 1992

Número 47

\section{SUMARIO}

Educación y transformación productiva con equidad. Fernando Fajnzylber.

El síndrome del "casillero vacío". P. van Dijck.

La consolidación de la democracia y del desarrollo en Chile. O. Sunkel.

Patrón de desarrollo y medio ambiente en Brasil. R. Guimarães.

Fundamentos y opciones para la integración de hoy. E. Lahera.

Globalización y convergencia: América Latina frente a un mundo en cambio. J.M. Benavente y P. West.

El escenario agrícola mundial en los años noventa. G. Di Girolamo.

La trayectoria rural de América Latina y el Caribe. E. Ortega.

Potencialidades y opciones de la agricultura mexicana. J. López.

La privatización de la telefonía argentina. A. Herrera.

Racionalizando la política social: evaluación y viabilidad. E. Cohen y $R$. Franco.

Economía política del Estado desarrollista en Brasil. J.L. Fiori.

Orientaciones para los colaboradores de la Revista de la CEPAL.

Publicaciones recientes de la CEPAL 
REVISTA DE LA GEPAL N 47

\section{La consolidación de la democracia y del desarrollo en Chile}

\author{
Osvaldo Sunkel*
}

La transición a la democracia en Chile se ha bogrado en forma excepcionalmente rápida y exitosa. En cambio, su consolidación está comenzando y enfrenta severos desafíos que exigirán esfuerzos de gran envergadura y complejidad en los años venideros.

En lo político, será preciso despejar las anomalias institucionales negociadas para facilitar la transición. superar los anacronismos acumulados antes y durante el largo interregno autoritario, y profundizar social y culturalmente el proceso democrático. En lo económico, será necesario fortalecer la apertura externa impulsando un desarrollo exportador "industrializante" - capaz de reforzar la dinámica estructural futura tanto en su inserción jnternacional como en sus vinculaciones y eslabonamientos internos- mediante una estrategia concertada de "desarrollo desde dentro". Fin to social, la mayor heterogeneidad estructural generada por la exigencia de competitividad internacional, exigirá un jedoblado estuerzo económico y social y la nuaxima eficacia en las políticas públicas. incluido un profundo cambis conceptual e institucional de ellas, para avanzar significativamente hacia los equilibrios macroseciales básicos. Lo anterior, unido a los vaivenes históricos entre los excesos del estatismo $y$ del neoliberalismo y a los nucvos desafios internos y externos, lleva a plantear la necesidad de una reforma del Estato. Este delse convertirse en la expresión institucional socialmente negociada de la interrelación cle los cambios polfticos, económicos y sociales indicados. Si estos se refuerzan reciprocamente, se potenciará la posibilidad de consolidar el desarrollo y la democracia. Si se falla en alguno de ellos, se podtá tener crecimiento sin democracia, o clemocracia sin creciniento, o en el peor de los casos, ni democracia ni crecimiento.

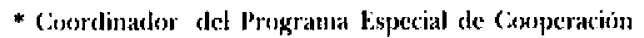
Acartómica ale la citist.

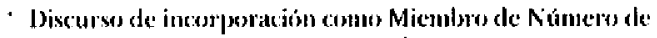
la Academia de ciencias Suciales del Justituto de (hile, pro-

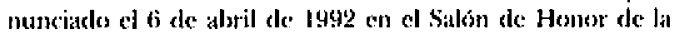
Lniversirlial de. Chile.
Desde la perspectiva del enfoque estructuralista latinoamericano, que utiliza un método histórico, multidisciplinario y transnacional, he venido examinando múltiples aspectos y etapas del desarrollo de la región a lo largo de las cuatro últimas décadas.

La más reciente se ha caracterizado por una crisis económica y social muy severa, y drásticas políticas de ajuste y reestructuración que generan serias tensiones políticas en nuestras democracias. Esto me ha llevado a concentrarme en el estudio de la problemática socioeconómica y política contemporánea y sus perspectivas y, en especial, en una revisión crítica del papel del Estado. Por ello he considerado oportuno en esta ocasión reflexionar sobre algunos de esos temas, que me parecen de especial relevancia en este momento de transición a la democracia en Chile.

En contraste con otros países de la región que han pasado por procesos similares, a dos años de recuperarse las instituciones democráticas fundamentales predomina ampliamente en el pais y entre los observadores internacionales la impresión de que la transición ha sido exitosa y que se encuentra en buenas condiciones para consolidarse en el futuro. Satisfechas las prioridades iniciales, las preocupaciones comienzan a desplazarse hacia planos más profundos, relacionados con el contenido socioeconómico, la naturaleza de la convivencia ciudadana y la institucionalidad política. Crece entonces la conciencia de que la consolidación democrática en Chile presenta deficiencias y problemas propios de un proceso que está en sus comienzos y que tiene aún un largo trecho por recorrer.

En este periodo inicial se ha privilegiado la búsqueda de acuerdos para llevar a cabo las transformaciones que la mayoría de los chilenos consideraba indispensables y urgentes en una primera etapa. En virtud de ello se reconoció explícitamente la necesidad de aceptar ciertas restricciones y aún deformaciones del régimen democrático, que se establecieron como condiciones esenciales de la transición por poderosos sectores vinculados al régimen anterior, profundamente desconfiados de lo que pudiera significar para ellos y para el pais la restauración democrática.

En estas circunstancias el nuevo gobierno ha debido infundir confianza a sectores claves de la economía y la política -como el empresariado nacional y extranjero, que ahora se constituye en un actor social predominante en la economía de mercado-, y en el decisivo mundo de las finan- 
zas internacionales, en los partidos de oposición y en las propias Fuerzas Armadas, recién desplazadas del gobierno.

Ha tenido que alentar también la moderación, la comprensión y el apoyo de los sectores sociales y políticos mayoritarios de centro y de izquierda. Estos habian sido sistemáticamente ignorados o perseguidos durante largo tiempo, restringiéndose su acceso y su participación en la convivencia cultural, social, económica y política del país, incluso por medio del exilio y la violación de los derechos humanos. Este fue especialmente el caso de los dirigentes y militantes de los partidos y movimientos de izquierda.

De esta manera, el espectro político del país, que antes del golpe militar extremaba las discrepancias y el conflicto, tiende ahora a converger hacia posiciones centristas. Las principales corrientes políticas se autodefinen como de centroderecha o de centro-izquierda, y hay incluso quienes se califican de "centro-centro". Esto es consecuencia directa de nuestra convulsionada historia de las últimas dos décadas y media, pero también de los trascendentales cambios ocurridos en el contexto geopolitico, ideológico y económico internacional. Así, la disposición prevaleciente en las corrientes políticas y los actores sociales más significativos ha sido la de atenuar, moderar y reducir las controversias, a menudo evitando enfrentarlas y postergándolas para el futuro.

Esta situación relativamente confortable no debe ni puede ser motivo de pasividad y complacencia. Por el contrario, constituye la base para un ejercicio necesario e impostergable: levantar la vista de lo inmediato y de lo urgente para dirigirla al futuro de mediano y largo plazo. No quisiera ser mal entendido ni parecer injusto, pues hay importantes iniciativas en ese sentido en variados ámbitos del quehacer nacional.

Sin embargo, tengo el arraigado convencimiento de que se ha vuelto prioritario, como una gran tarea nacional, comenzar a preocuparse más explícita, sistemática y decididamente de la construcción de un Chile finisecular que entre al siglo xxı con una democracia institucionalmente normalizada, socialmente integrada y políticamente cohesionada; con una economía dinámica, flexible e innovadora, capaz de erradicar la pobreza y crear las condiciones para una mayor igualdad de oportunidades, y de generar a la vez nuevas capacidades para continuar conquistando posi- ciones en la economía mundial. Todo ello acompañado de una renovación cultural que logre conjugar las tendencias homogeneizantes internacionales con la variedad y el pluralismo, procurando construir una identidad nacional sobre la base de los valores de una cultura auténticamente democrática, que combine lo propio y nuestro con lo universal, los valores humanos y espirituales con las exigencias concretas de la ciencia, la tecnología y la organización eficaz, y la tradición con la innovación y la modernidad.

En el limitado tiempo disponible, examinaré brevemente cuatro temas: uno de carácter politico, otro económico, un tercero social y el último derivado de los anteriores, sobre el papel del Estado. Considero esencial su esclarecimiento para que, adelantada la transición, se avance hacia la consolidación de la democracia y el desarrollo.

En el plano politico el proceso ha sido complejo, predominando los aspectos positivos sobre algunas graves falencias. Pero, en definitiva, las autoridades de los poderes ejecutivo y legislativo han sido elegidas en forma legítima; se han restablecido las libertades fundamentales de opinión, de reunión y de asociación; existen partidos políticos que desempeñan libremente sus funciones de apoyo u oposición al gobierno; hay un Estado de derecho que opera razonablemente, con la debida separación de los poderes del Estado, y se han restablecido los derechos humanos y ciudadanos. Desde esta perspectiva, la de los procedimientos y el modo de convivencia política inherentes a la democracia, podría incluso aceptarse que la transición se ha consumado en gran medida.

Pero es también evidente que algunos de estos procedimientos adolecen de serias deficiencias. Algunas de ellas son el producto de la institucionalidad heredada del gobierno anterior y de las condiciones que se negociaron para facilitar la transición. Son bien conocidas. Para nuestros propósitos basta destacar que su efecto es crear situaciones de privilegio político, económi$c o$, institucional y judicial para quienes fueron actores sociales protagónicos del gobierno militar.

En la medida en que la transición a la democracia progresa satisfactoriamente, crece su aceptación entre los que desconfiaban de ella. Pero comienza a manifestarse la inquietud de otros sectores sociales que, satisfecho su anhelo de re- 
cuperar el régimen político democrático, aspiran a que se traduzca en mayores realizaciones en los planos económico, social, cultural y judicial. Así, la razón de ser de esas salvaguardias va desapareciendo para algunos, mientras se agudiza en otros su percepción de que representan anomalías cada vez menos justificables.

Ellas cumplieron un papel estabilizador en las fases iniciales de la transición. Pero comienzan a tener el efecto contrario, porque introducen un sesgo sistemático en favor de las corrientes y actores políticos minoritarios que apoyaron al régimen militar, y porque suelen producir turbulencias internas e internacionales en las relaciones cívico-militares en circunstancias que no debieran provocar mayor intranquilidad si esas anomalías fueran despejadas. Constituyen así una persistente fuente de irritación, de frustración, de conflicto y de presiones para la normalización del régimen político y para reformar la Constitución y el Poder Judicial.

Hay otros problemas políticos, de naturaleza más genérica, que tienen que ver con el proceso permanente de perfeccionamiento de la democracia. Se trata, por ejemplo, de la posibilidad de reformar el régimen presidencial para darle mayor flexibilidad y mejorar el equilibrio entre los poderes ejecutivo y legislativo; de lograr una mayor participación y representación popular y de los diferentes agentes sociales al nivel nacional, de las regiones y del gobierno local; de una legislación más apropiada a las realidades y valores sociales en materias tales como la condición de la mujer y la juventud, así como respecto del aborto y el divorcio; de la necesidad urgente de revisar la legislación y la institucionalidad ambiental; de la modernización de la ad ministración y gestión públicas en general, en particular en cuanto concierne a los sectores sociales. Entre ellos creo que requiere atención prioritaria la deplorable condición de los servicios judiciales, y sobre todo su incapacidad congénita para atender las necesidades de los sectores populares.

Estos y otros temas similares se han venido haciendo presentes con creciente fuerza en el debate público y algunos han logrado ser incorporados en las agendas políticas y han sido, son o serán, materia de legislación. De esta manera se van configurando las características institucionales más permanentes del Estado, en circunstancias que el sesgo político antes aludido signi- fica objetivamente que el proceso parlamentario no tiene suficiente representatividad democtática. Ello podría tener una grave consecuencia: que amplios sectores ciudadanos subrepresentados consideren que la institucionalidad emergente carece de legitimidad política.

A las limitaciones del Poder Legislativo, derivadas del peculiar sistema electoral y la institución de los senadores designados, se agregan las restricciones constitucionales y legales que cercenan importantes facultades del Poder Ejecutivo, especialmente en su relación con las Fuerzas Armadas. Aún más grave, en mi opinión, es el caso del Poder Judicial y en especial de la Corte Suprema de Justicia. Su reconocido anacronismo concita en la ciudadanía una actitud escéptica acerca de los atributos en que reside su autoridad, respetabilidad y eficacia. Esto debilita el Estado de Derecho, esencia de la democracia. Por ello pienso que si los poderes del Estado mantienen las características señaladas, se entorpecerá seriamente la consolidación de la democracia en la conciencia ciudadana.

La principal tarea política actual es superar esta situación anómala. Para ello es preciso persistir infatigablemente en las actitudes, disposiciones y procedimientos de diálogo y negociación que tanto éxito tuvieron en superar la crítica fase inicial de la transición. Es necesario además avanzar en su extensión y profundización social desde las elites políticas hacia el conjunto de los sectores sociales y la ciudadanía en general. Hay que asumir en plenitud los valores de la cultura democrática y perfeccionar la representatividad y eficacia de las instituciones que regulan su funcionamiento. A los dirigentes sociales en general, y en especial a los partidos políticos, corresponde en esta tarea una responsabilidad histórica. Sobre todo cuando la controversia política se acentúa en vísperas de procesos eleccionarios o de debates sobre reformas de fondo.

En sus aspectos económicos, la transición chilena es aún más elogiada que en los políticos, pues el contraste con la mayoría de los países de la región es especialmente marcado. No cabe duda de que durante el régimen militar se lograron rectificaciones fundamentales e impostergables en aspectos claves de la política económica. Pero quedan pendientes tareas muy decisivas. Sin desconocer las importantes iniciativas en marcha, me parece imprescindible llamar también la atención sobre 
la necesidad de acentuar y generalizar la preocupación y la reflexión por los problemas del mediano y largo plazo.

Chile es un pats pequeño, alejado geográficamente de los grandes centros, pero cada vez más incorporado a los circuitos transnacionales de la cultura, el medio ambiente, la tecnología, la economía y la política. Este es un fenómeno inevitable e irreversible de la realidad contemporánea, que presenta ventajas e inconvenientes. Para minimizar los últimos y aprovechar las primeras, el país deberá realizar un esfuerzo mayúsculo con el fin de responder al desafío irrenunciable de participar en una sociedad mundial que se globaliza aceleradamente. Como carecemos de una dimensión territorial o demográfica significativa, o de una localización geográfica estratégica, sólo podremos interactuar ventajosamente con el mundo sobre la base de la calidad, la creatividad, la eficacia, la seriedad y la competitividad en todas nuestras formas internacionales de expresión. Esto requiere un grado excepcional de cohesión, disciplina y cooperación social, lo que plantea exigencias sobre las que insistiré más adelante.

En materia de internacionalización, no he podido resistir la tentación de mencionar una coincidencia que sólo percibí al escribir estas líneas, ya establecidos el lugar y la fecha de esta ceremonia. La única ocasión anterior en que tuve el honor de ocupar este estrado fue el 17 de noviembre de 1966, para dictar una de las conferencias inaugurales del Instituto de Estudios Internacionales, cuyos 25 años se celebraron hace poco en este mismo salón. Mi presentación se titułó "Política nacional de desarrollo y dependencia externa".' En ella señalaba que el ciclo expansivo de la industrialización por sustitución de importaciones se agotaba, y se tornaba im. prescindible un radical vuelco hacia una estrategia exportadora. De hecho, la sección correspondiente de mi trabajo se titulaba "exportar u morir". Destacaba también el fenómeno emergente de la gran expansión de las empresas transnacionales y los peligros que entrañaban, así como las oportunidades que of recian. Para aprovechar estas últimas en materia de transferencia de tecnología y de promoción de exportaciones, pro-

\footnotetext{
'Apareció en Estudion Intemaciomales, Instituto de Estur dios Internacionales, Santiago de (hile, abril te 1967.
}

ponía una fórmula de asociación que denominé "co-producción", lo que viene a ser la actual jointventure.

El éxito logrado en los últimos años por la economía chilena en los mercados internacionales se ha basado, por una parte, principalmente en el reconocimiento de la necesidad imprescindible de pasar de una estrategia de desarrollo hacia adentro a otra de inserción en una nueva realidad internacional, que ya se percibía claramente en esa época. $\mathrm{Y}$ por otra parte, en establecer un marco apropiado de condiciones macroeconómicas, mirar con mayor confianza y ampliar el papel del mercado y los agentes económicos privados, y lograr un gran esfuerzo de innovación empresarial. Llevar a cabo este impostergable cambio de orientación fue, a mi juicio, la función más importante que cumplió la política económica del gobierno militar.

Es justo reconocer que se contaba para ello con un considerable acervo de potencial productivo heredado de las décadas anteriores en materia de recursos naturales evaluados, de infraestructura energética y de transportes, de capacidad de producción industrial y silvoagropecuaria, de empresarios experimentados y de recursos humanos calificados. Se habian realizado además cambios estructurales e institucionales de mucha trascendencia que permitieron en definitiva su mejor aprovechamiento. En términos técnicos, existía un conjunto nuevo y más favorable de condiciones iniciales para el crecimiento.

Por otra parte, dicha reorientación económica significó también ingentes sacrificios sociales: un prolongado período de elevado desempleo y considerables reducciones de los salarios reales, junto a tasas de rentabilidad anormalmente elevadas, con el consiguiente deterioro en la distribución del ingreso y una fuerte concentración de la propiedad.

El aspecto más positivo de estas transformaciones fue un gran salto cualitativo y cuantitativo en la inserción internacional de la economía chilena. Pero tampoco en esta materia se puede ser complaciente. Nada garantiza que ese dinamismo sea perdurable, porque contiene tendencias contradictorias: por un lado, un progrésivo proceso de aprendizaje en la conquista de mercados externos y en el desarrollo de vinculaciones internacionales, que será preciso reforzar para que se convierta en acumulativo; por el otro, una pro- 
bable desaceleración en la medida en que se vayan agotando los impulsos derivados de los cambios en las condiciones iniciales. Después de una primera fase excepcional, muchos de éstos se encuentran, o pueden entrar, en la etapa de rendimientos decrecientes.

Los principales cambios institucionales y en la orientación de las políticas económicas ya se realizaron. Las excepcionales tasas de rentabilidad tienden a nivelarse por la presión a la baja del tipo de cambio real y el aumento de la competencia interna y externa. Los salarios vuelven a elevarse con la disminución del desempleo abierto y la reorganización de la clase trabajadora. Los mercados externos más asequibles comienzan a saturarse y surgen nuevos competidores provenientes de países que han adoptado o están adoptando estrategias exportadoras similares. La capacidad instalada de infraestructura y producción llega a sus límites. Los recursos naturales renovables se resienten con la sobreexplotación y los no renovables tienden al agotamiento. El dinamismo empresarial y la capacidad innovadora, radicados sobre todo - aunque no en forma exclusiva- en la gran empresa, enfrentan el desafío de vincularse y extenderse a la empresa mediana y pequeña, e incluso a la microempresa.

Se necesitan nuevas iniciativas y esfuerzos adicionales, tanto para contrarrestar estas restricciones, como para apoyar las nuevas capacidades adquiridas. Porque no basta con el meritorio nivel alcanzado por las exportaciones, sino que es preciso mantener y aun incrementar su ritmo de expansión. En un contexto dinámico, crecer como los demás significa quedarse en el mismo lugar; para ganar posiciones es preciso avanzar con mayor velocidad relativa. No es suficiente continuar por las vías ya establecidas; es necesario crear una dinámica de transformación estructural recurrente en materia de mercados, productos, procesos, organización, tecnología y recursos.

Esto significa moderar el consumismo y aumentar el esfuerzo de inversión y ahorro; acentuar el proceso de innovación, incorporación, adaptación y aprovechamiento del conocimiento cientifico y tecnológico; penetrar nuevos mercados y profundizar los actuales; dinamizar y modernizar los sectores productivos internos y los estratos empresariales rezagados mediante su vinculación con el sector exportador; incorporar el sector productivo informal a la modernidad; explotar en forma sustentable el potencial productivo de los recursos renovables mediante una gestión que preserve los ecosistemas de que depende su supervivencia, así como reemplazar los recursos no renovables que tiendan a agotarse, y transitar hacia la exportación de productos con mayor valor agregado y contenido tecnológico.

Un aspecto de particular importancia en las economías exportadoras exitosas ha sido el de los cambios en la organización de las empresas, tanto dentro de ellas como en sus relaciones recíprocas y en sus relaciones con el Estado y los trabajadores. Este último aspecto incluye la estabilidad, la dignificación y el perfeccionamiento profesional de los obreros y su participación y colaboración activa con un empresariado renovado en la gestión y el perfeccionamiento productivo, factores que elevan la productividad y contribuyen decisivamente a lograr flexibilidad, eficiencia, disciplina y cooperación.

En definitiva, se trata de impulsar un desarrollo exportador "industrializante", mediante políticas destinadas a aumentar la proporción de las exportaciones de mayor dinamismo en el comercio internacional, y a eslabonar otras ramas productivas y estratos empresariales internos a la expansión del sector exportador. ${ }^{2}$

Este conjunto de políticas de carácter estructural e institucional tiene actualmente especial importancia porque el margen de maniobra de las políticas económicas tradicionales es ahora, por razones internas e internacionales, sumamente estrecho.

En algunos de estos aspectos existen y se proponen iniciativas importantes, tanto privadas como públicas. Pero preocupa la falta de una conciencia nacional generalizada sobre la necesidad de un renovado esfuerzo colectivo de suficiente envergadura, persistencia y coherencia. Este debiera involucrar a los diferentes actores económicos y sociales en un proceso informado y sistemático de exploración prospectiva, de indagación sobre escenarios posibles y probables, de reflexión compartida sobre orientaciones matrices y acciones prioritarias con miras al mediano

\footnotetext{
${ }^{2}$ Osvaldo Sunkel (ed.), El desarrollo desde deniro; un enfoque nevestructuralista para la América Latina, Fondo de Cultura Económica, Serie Lecturas, México, 1991.
} 
y largo plazo. Se trata de concentrar los recursos limitados para encontrar y aprovechar en forma óptima los potenciales productivos y las oportunidades de un entorno internacional muy competitivo y difícil. También de comprender que no es posible responder a todas las demandas sociales en forma satisfactoria, simultánea e inmediata, por lo que es inescapable definir prioridades y buscar compensaciones concretas entre lo que es factible en el presente y lo que sólo se podrá obtener gradualmente. Esto exige elaborar escenarios de futuro en que los diferentes sectores de la sociedad chilena, en especial los más desfavorecidos, reconozcan un lugar por el que valga la pena esforzarse.

Hemos aprendido que el mercado constituye un sistema de señales insustituible para ordenar el tráfico económico. Pero también que es insuficiente para resolver este tipo de cuestiones, que requieren grandes decisiones estratégicas. Estas debieran elaborarse colectivamente en una instancia de planificación anticipativa y articuladora, que estimule y concite la generación de propuestas e iniciativas complementarias a las que surjan del mercado. Ninguna organización, insitución o empresa moderna carece de esa función y su correspondiente institucionalidad. Chile inventó en el pasado una institución de planificación ejemplar para cumplir una función que tuvo importancia historica: la Corporación de Fomento de la Producción. Tendrá que inventar una nueva institucionalidad de acuerdo a las realidades y necesidades del presente $y$ las que se anticipan para el futuro. También aquí, desde sus propias perspectivas, los actores sociales y el Estado, junto a los partidos políticos, tienen una contribución fundamental que hacer.

Paso ahora a la cuestión social, que es sin duda la más dificil. El imprescindible esfuerzo de inserción internacional en que está empeñado el país no podrá ser exitoso ni sostenible si no va acompañado de un cambio profundo en las formas de organización y cooperación internas. Se ha prestado poca atención al hecho de que la dinámica de la integración transnacional genera con frecuencia condiciones de segregación social interna. ${ }^{3}$ Esto se aprecia en los diferentes sectores

\footnotetext{
"Ostaldo Sunkel, Integración transnacional y desintegración nacional, Estudios Internaciomales, Santiago, eneromarzo de 1971 .
}

de la actividad económica, en donde se establecen nuevas empresas y se reestructuran las de mayor Cupacidad innovadora para competir en los mercados internacionales y en el interno. Ello significa nuevos empleos bien remunerados de alta productividad para algunos, pero también el desempleo de los trabajadores desplazados de las empresas reestructuradas y de las que no tesisten la competencia.

Se producen así tendencias divergentes entre los que ingresan al segmento moderno de elevada productividad en proceso de internacionalización y los que descienden al mundo del empleo en actividades de baja productividad, al subempleo o el empleo por cuenta propia, engrosando la economía informal y la pobreza. Por desgracia, entregados al juego espontáneo del mercado, los primeros tienden a ser menos que los segundos, dado el crecimiento de la población y la fuerza de trabajo, las severas exigencias de reestructuración derivadas de las políticas de liberalización, privatización y competencia internacional, la masiva incorporación de tecnologia que hace uso intensivo de capital, el insuficiente esfuerzo de inversión, y la falta de calificaciones, educación y hábitos laborales de gran parte de la población activa.

De este modo se configura una nueva situación de heterogeneidad estructural con características diferentes a las del pasado. Discrimina en contra de las personas de mayor edad, los numerosos contingentes de jóvenes sin experiencia laboral, y las mujeres, sobre todo si son jefes de hogar y carecen de conocimientos adecuados. Favorece en cambio a los adultos urbanos con mejores calificaciones y conocimientos, mayor espíritu de iniciativa y capacidad de acceder a los mercados segmentados de trabajo.

Tenemos así, en diferentes sectores productivos, en las regiones, en las áreas urbanas y rurales y en los distintos estratos sociales, en proporciones muy desiguales, la coexistencia de modernidad y atraso en las actividades productivas, de riqueza y pobreza en los niveles de ingreso, y de agudos contrastes ambientales, que determinan tremendas diferencias culturales, institucionales, políticas y demográficas que tienden a su respectiva autorreproducción. De modo que las nuevas generaciones que viven en la pobreza tienen escasas posibilidades de superarla. El crecimiento económico, sin duda condición indispen- 
sable para enfrentar esta situación, no constituye, por sí mismo, la solución. En ausencia de cambios institucionales y eficaces políticas económicas y sociales, puede incluso acentuar las desigualdades y contribuir a la discriminación y el conflicto social, a los comportamientos delictivos, al enfrentamiento político y, en general, a la insatisfacción, la inestabilidad y la violencia social. En definitiva, a amenazar lo que se ha logrado en los últimos años: una incipiente democracia, algunos consensos fundamentales y el indispensable crecimiento económico.

Sabemos que se han hecho y se están haciendo esfuerzos sustanciales en esta materia. Entre ellos merece recalcarse el cambio de acento desde medidas básicamente asistenciales a políticas productivas, destinadas a crear las condiciones para la superación permanente de la marginalidad. Pero la tarea es de una envergadura abrumadora. No sólo se trata de los enormes déficit acumulados: la "vieja pobreza" heredada del modelo económico anterior, y la "nueva pobreza" generada por el cambio de modelo, la crisis, el ajuste y la reestructuración. Además, es preciso quebrar y revertir los mecanismos reproductores de la desigualdad que derivan de las condiciones diferenciales de acceso, calidad, eficacia y permanencia, tanto en las infraestructuras y los servicios asistenciales, como en los que apoyan las actividades productivas.

Se requieren nuevas modalidades institucionales públicas y privadas. En especial, esfuerzos imaginativos adicionales del sector privado en el campo de las relaciones laborales y de cooperación dentro de las empresas, y entre ellas, relaciones que se han convertido en uno de los factores cruciales de superioridad y éxito empresarial. También un cambio de prioridades y mayor eficacia en el gasto y la gestión públicos, así como transferencias adicionales de activos y de ingresos entre sectores productivos, regiones y estratos sociales, mediante una progresividad eficaz en los ingresos y en los gastos públicos.

Aparte de sus fundamentos éticos, la eliminación de la pobreza, la atenuación de las desigualdades, la búsqueda de la equidad y la apertura de un horizonte atractivo de oportunidades constituyen requisitos imperiosos para la consolidación de la democracia y el afianzamiento de una economía dinámica y moderna.

Permítaseme recalcar la necesidad de una preocupación preferente por la juventud, que constituye una gran proporción de la población. Es la más afectada por el desempleo y el desaliento, la que está más expuesta a todo tipo de riesgos y la que mayor necesidad tiene de oportunidades, y sobre todo de aliento, comprensión y esperanza.

Pienso que la envergadura de la tarea social exige un profundo cambio conceptual e institucional. Adviértase, por ejemplo, que la política económica tiene objetivos prioritarios bien precisos de crecimiento, equilibrio macroeconómico y estabilidad de precios. Para ello existe una institucionalidad conformada por el Ministerio de Hacienda, el Banco Central, la Dirección de Presupuestos y otros organismos, y los correspondientes procedimientos de control de actividades, programas y proyectos, de evaluación de resultados y de monitoreo de una información estadística amplia y oportuna. Hay incluso instituciones internacionales, públicas y privadas, que controlan, complementan y refuerzan las internas.

En materia social, que debiera ser en realidad el objetivo último de la política económica, se requiere algo equivalente. Así como todos aceptan la necesidad de tener equilibrios macroeconómicos básicos, es preciso lograr también "equilibrios macrosociales básicos". Esta noción está implicita en la acción política de más alto nivel y debiera reflejarse en una organización institucional que le dé la mayor eficacia y coherencia a las tareas de gobierno en estas materias. No obstante los loables esfuerzos y logros de coordinación, las políticas y la acción social están de hecho organizadas sectorialmente, a través de múltiples programas en diversos ministerios. Además, son afectadas, indirecta y la mayoria de las veces implícitamente, por la vía de las políticas económicas. Esta debilidad institucional resulta de haberse supuesto históricamente que el crecimiento y la estabilidad económicos derivarían inevitablemente en el mejoramiento social. Como ese supuesto no se cumplió en la práctica, se fueron ampliando con el tiempo los servicios sociales —dando por resultado un conjunto de políticas sectoriales complementadas con programas y proyectos especiales - y en períodos más recientes, incluso se ha recurrido a la privatización de parte de estos servicios para atender los grupos de mayores ingresos. 
Es imprescindible establecer una institucionalidad de suficiente nivel político y capacidad operacional para integrar eficazmente las políticas sociales entre sí y con la política económica. Ello presupone una teorización y conceptualización que precise objetivos prioritarios, identifique y especifique sus contenidos y factores determinantes, y permita la formulación de las políticas correspondientes, incluyendo los sistemas de información, de gestión, de seguimiento y de evaluación. Se trata, a mi juicio, de una tarea indispensable para avanzar más decisivamente en la eliminación de la pobreza, la atenuación de las desigualdades y las injusticias sociales, y la apertura de un horizonte de oportunidades atractivo sobre todo para la juventud, sin lo cual difícilmente se logrará la estabilidad y la cooperación social necesarias para consolidar la democracia y el desarrollo.

$Y$ esto me lleva a la necesidad de reconsiderar crítica y desapasionadamente el papel del Estado. En primer lugar, como espero haberlo demostrado, la acción y la reforma del Estado en los planos político, económico y social son imprescindibles si han de consolidarse conjuntamente aquellos objetivos. En segundo lugar, al Estado le corresponde ser en buena parte la expresión institucional orgánica de la interrelación entre dichos planos. Si estas condiciones se refuerzan mutuamente, se potenciará sinérgicamente la posibilidad de consolidar el desarrollo y la democracia. Si se falla en alguna de esas tareas se puede tener crecimiento sin democracia o democracia sin crecimiento, o incluso, en el peor de los casos, ni democracia ni crecimiento. En tercer lugar, es indispensable despejar la desmesurada ideologización que prevalece actualmente en esta materia, con el fin de poder debatir racionalmente las orientaciones generales que debieran guiar su reorganización en el futuro.

Para ello también es conveniente levantar la vista de los problemas y tareas del presente y examinar el cambiante papel del Estado desde una perspectiva histórica. ${ }^{4}$

Después de la gran depresión mundial de inicios de los años treinta, el Estado pasó a de-

\footnotetext{
${ }^{4}$ Osvaldo Sunkel, Auge, crisis y renovación del Estado: una perspectiva de largo plazo, en Matías Tagle (ed.) Los desaforos del Estado en las años 90, Foro 90-(1): Santiago de Chile, 1991.
}

sempeñar un papel protagónico en el desarrollo y transformación estructural de la economía y sociedad chilenas. Asumió nuevas funciones de intervención en los mercados de bienes y servicios, para reorientar la economía hacia la industrialización y la modernización; de financiamiento de proyectos y programas de inversión de largo plazo, para suplir la inexistencia de un mercado financiero que apoyara el desarrollo de la actividad privada en la industria y otros sectores; de redistribución de ingresos, creando y ampliando la infraestructura y los servicios sociales públicos de salud, educación y cultura, vivienda y urbanismo, seguridad y previsión social; de inversión estatal en infraestructura con el fin de integrar físicamente el mercado interno mediante la modernización y ampliación de los servicios nacionales de transportes, comunicaciones y energía; de creación de empresas públicas en industrias que no interesaban o no estaban al alcance de la iniciativa privada; de generación de oportunidades de empleo en las actividades señaladas, lo que contribuyó a la formación de recursos humanos calificados, de un importante sector asalariado organizado y de una amplia clase media de empresarios, empleados, técnicos y profesionales.

En esto Chile no hacía más que seguir tendencias mundiales. Después de la edad de oro del laissez faire decimonónico sobrevino una profunda crisis del capitalismo que se prolongó desde la primera hasta después de la segunda guerra mundial, pasando por los turbulentos años veinte y la gran crisis de los treinta. Durante su vigencia tuvieron lugar grandes cambios económicos, sociales y políticos que buscaban enfrentar y revertir dicha crisis y sus consecuencias.

El primero de esos grandes cambios fue la Revolución Socialista. Como es bien sabido, en la transformación económica de la Unión Soviética, y de los países en que se impuso su modelo, el Estado asumió el control total de la economía y mediante una planificación centralizada realizó profundas transformaciones estructurales e impuso procesos de crecimiento económico y mejoramiento social a marcha forzada.

Dentro del área capitalista también se recurrió a la acción del Estado para enfrentar sus dificultades. Es el caso de los regímenes corporativos fascistas que se establecieron en gran parte de Europa en los años veinte y treinta. En los 
países escandinavos y anglosajones emergieron el Welfare State y el New Deal, que significaron una intervención sin precedentes del Estado en la economía para superar la crisis, redistribuir el ingreso y remediar la inestabilidad cíclica del capitalismo. En los países subdesarrollados de América Latina, Africa y Asia surgió el Estado desarrollista, para llevar a cabo transformaciones modernizadoras en estas atrasadas sociedades periféricas.

En contraste con la leyenda negra que se ha tejido en años recientes sobre este periodo, la evidencia empírica demuestra irrefutablemente que aquellas políticas fueron muy exitosas durante varias décadas. Desde fines de los años cuarenta hasta los setenta se registraron tasas de crecimiento económico y de mejoramiento del bienestar material sin precedentes históricos en la mayoría de los países capitalistas, tanto desarrollados como subdesarrollados. Aunque parezca paradójico a la luz de su descalabro actual, lo mismo sucedió en la mayoría de los países socialistas.

No obstante, junto a una necesaria revalorización del rol del Estado en ese período, se requiere igualmente su revisión crítica, puesto que dicho ciclo histórico entró en decadencia y llegó a su fin en el decenio de los años setenta. En efecto, con el cúmulo de nuevas funciones que el Estado fue asumiendo se generaron tendencias contradictorias que se fueron agudizando con el tiempo.

En lo económico, una intervención cada vez mayor y menos justificada en los mercados, entorpeciendo y desvirtuando su indispensable función complementaria en la asignación de los recursos productivos, con crecientes efectos negativos sobre su utilización más adecuada, la eficiencia, la competitividad y el crecimiento. En lo financiero, una sed insaciable de captación de recursos frente a crecientes dificultades tributarias, acentuando presiones inflacionarias, demandas salariales y reducciones en los márgenes de rentabilidad, con el consiguiente desaliento del sector privado. En lo institucional, una excesiva burocratización, interferencia y control administrativos en la vida económica y social, que generaron cada vez mayor rigidez y arbitrariedad, cuestionando la legitimidad política del Estado. En lo socioeconómico, una agudización del conflicto entre el abrumador aparato estatal y el fortalecimiento de las aspiraciones de mayor participación, de la descentralización, y de la libertad tanto individual como de las organizaciones ciudadanas. En las relaciones internacionales, la acentuación del desajuste entre los procesos de transnacionalización de la economía, las finanzas, la sociedad y la cultura frente a los esfuerzos del Estado nacional por restringirlos, acotarlos y controlarlos. Estas y otras contradicciones terminaron por entorpecer la fase expansiva del intervencionismo estatal y dieron lugar a su crisis terminal.

Las contradicciones antes mencionadas estimularon algunas importantes reorientaciones de signo liberalizante y racionalizador en los años sesenta. Pero con el advenimiento del gobierno de la Unidad Popular las funciones del Estado se ampliaron desmesuradamente, incluso a la sustitución del mercado mediante el control generalizado de precios y la estatización de la banca y de gran parte del aparato productivo, generándose un caos económico-financiero que resultó social y políticamente insostenible.

El gobierno militar adoptó un programa radicalmente opuesto, caracterizado por apoyo irrestricto e indiscriminado al mecanismo del mercado y a la empresa privada, mediante la liberalización, la desregulación, la apertura externa, la privatización de empresas y servicios públicos y la reducción del tamaño y las funciones del Estado. No sólo revirtió así las políticas del gobierno socialista, sino que desmanteló y reemplazó incluso las formas más moderadas de intervencionismo estatal de los decenios previos.

Este conjunto de políticas se llevó a cabo con un sesgo fuertemente regresivo, cargando todo el peso del drástico proceso de ajuste y reestructuración sobre las clases populares y los sectores medios. Aumentó considerablemente el desempleo, el subempleo y los sectores informales; se redujeron sus ingresos y salarios; se incrementó su carga tributaria; se restringieron, deterioraron y encarecieron los servicios públicos de educación, salud, vivienda y previsión social. Todo esto en agudo contraste con los sustanciales beneficios que recibieron los sectores minoritarios que disfrutaban de condiciones privilegiadas $\mathrm{pa}^{-}$ ra acceder a los procesos de privatización, desregulación y apertura, y participar y obtener beneficios de ellos.

En definitiva, la eclosión de la crisis estruc- 
tural del Estado en los años ochenta tuvo a mi parecer tres raíces principales. La primera, la más genérica y profunda, fue la tendencia de largo plazo de auge y decadencia del ciclo estatista, que comenzó en los años interbélicos y finalizó en los años setenta. La segunda fue el generalizado y fallido intento de estatización y socialización impulsado por el gobierno de la Unidad Popular entre 1970 y 1973. La tercera se originó en las drásticas políticas neoliberales aplicadas desde 1975 y reforzadas posteriormente con motivo de la crisis de la deuda y las políticas de ajuste y reestructuración.

Los agudos movimientos pendulares que ha experimentado el papel del Estado en Chile en su historia reciente han tenido efectos heterogéneos y complejos sobre sus características estructurales, institucionales y de funcionamiento. No se dispone todavía de un diagnóstico realista, equilibrado y detallado de la verdadera naturaleza del aparato estatal que hemos heredado. Entretanto, enfrentamos nuevas condiciones históricas y se presentan problemas y retos inéditos para el desarrollo nacional y para su eficaz interacción con el contexto mundial, entre ellos los que he señalado en las secciones anteriores. Ello me lleva finalmente a plantear la necesidad urgente de enfrentar en toda su amplitud $y$ envergadura el tema de la reforma del Estado.

Es preciso abrir un debate amplio, pluralista y bien informado sobre la naturaleza y características que éste debiera adquirir en el futuro para superar sus actuales deficiencias y respon- der en forma adecuada, entre otros, a los nuevos objetivos, realidades, desafíos y tareas que he destacado en esta presentación. Será preciso hacer un máximo esfuerzo colectivo para confrontar los intereses de los grupos de presión con el bien social común, para identificar y superar hasta donde sea posible los sesgos ideológicos que caracterizan a las diferentes escuelas de pensamiento sobre la materia, y para apelar al mayor realismo posible, apoyándonos sobre todo en el examen crítico y desapasionado de nuestra propia experiencia, así como en la de otros países. Contamos para ello, no obstante sus desvios, vaivenes y detractores actuales, con una respetable y fructífera tradición de servicio público y de un "Estado en forma", como lo calificó tempranamente Alberto Edwards. La trayectoria del Estado en toda nuestra historia republicana merece un profundo respeto, que puede y debe recuperarse. De hecho, aun cuando haya perdido importantes funciones, representa sin duda, si se me perdona una expresión "economicista", una de las más importantes ventajas comparativas de nuestro país.

La problemática del Estado, junto a las que he planteado en los planos politico, económico y social, constituyen, en mi opinión, los principales desafios, y su resolución las tareas más cruciales, para que la exitosa transición que hemos experimentado hasta ahora se convierta efectivamente, como casi todos deseamos, en un proceso de consolidación de la democracia y del desarrollo en Chile. 